\title{
Relação entre as Características da Empresa, do Comitê de Auditoria e do Auditor Independente com o Prazo de Publicação das Demonstrações Financeiras
}

\author{
Resumo \\ O objetivo do estudo foi verificar a relação entre as características \\ da empresa, do comitê de auditoria e do auditor independente, \\ com o prazo de publicação das demonstrações financeiras das \\ empresas listadas na BM\&FBOVESPA. Utilizou-se de pesquisa \\ descritiva quanto ao objetivo, documental em relação aos \\ procedimentos e com abordagem quantitativa. Foi utilizada \\ uma amostra de 64 empresas para cada ano de análise, que \\ compreendeu o período de 2010 a 2012. Para a análise dos dados, \\ foi utilizada regressão linear múltipla, por meio do software \\ SPSS $^{\circ}$. Os resultados demonstram que o prazo de divulgação \\ das demonstrações financeiras possui relação significativa com \\ o endividamento, o setor da empresa, os honorários de não \\ auditoria e se a empresa é auditada por Big Four. Empresas \\ endividadas ou que pagam altos honorários de não auditoria \\ tendem a divulgar tardiamente suas informações. Se auditadas \\ por Big Four ou pertencentes aos setores de bens industriais, \\ tecnologia da informação, construção e transporte, tendem a \\ divulgar suas demonstrações financeiras em menor tempo.
}

Palavras-chaves: Comitê de Auditoria, Prazo de Publicação, Demonstrações Financeiras.

\begin{abstract}
Paulo Roberto da Cunha Doutor em Ciências Contábeis pela Universidade Regional de Blumenau (Furb) e professor da FURB e da Universidade do Estado de Santa Catarina (Udesc). Contato: Rua Antônio da Veiga, 140, Victor Konder, Blumenau-SC, CEP: 89012-900. E-mail: pauloccsa@furb.br
\end{abstract}

Caroline Sulzbach Pletsch Mestre em Ciências Contábeis pela Universidade Regional de Blumenau (Furb) e professora da Universidade do Estado de Santa Catarina (Udesc). Contato: Rua Dr. Getúlio Vargas, 2822, Bela Vista, IbiramaSC, CEP: 89140-000.

E-mail: carol_spletsch@yahoo.com.br

\section{Alini da Silva}

Mestre em Ciências Contábeis pela Universidade Regional de Blumenau (Furb) e professora da Universidade Regional Integrada do Alto Uruguai e das Missões. Contato: Av. Assis Brasil, 709, Itapagé, Frederico Westphalen-SC, CEP: 98400-000. E-mail: alinicont@gmail.com 


\section{Introdução}

As demonstrações financeiras são elaboradas e divulgadas com o objetivo de fornecer informações econômico-financeiras que sejam úteis para a tomada de decisão aos diferentes usuários. Para que as informações sejam úteis, o CPC 00 (Pronunciamento Técnico CPC 00, 2011) menciona que estas precisam ser relevantes, terem representação fidedigna, serem comparáveis, verificáveis, compreensíveis e tempestivas.

Fornecer informações que auxiliem os usuários na tomada de decisão é o objetivo principal das demonstrações financeiras e, dessa forma, essas informações precisam ser divulgadas em tempo hábil, serem tempestivas, caso contrário, perdem seu valor, pois informação defasada não contribui para a tomada de decisão (Al-Ajmi, 2008).

Soltani (2002) destaca que a pontualidade das demonstrações financeiras é uma característica qualitativa, relevante para avaliar a utilidade da informação contábil. A pontualidade das demonstrações financeiras é reconhecida pelos profissionais como uma característica importante para a informação (Al-Ajmi, 2008) e para que um mercado de capitais funcione bem (Afify, 2009).

Neste aspecto relacionado à data de publicação das demonstrações financeiras, pesquisas apontam que as empresas tendem a divulgar as informações positivas mais rapidamente do que as informações negativas (Cullinan, Wang, Yang \& Zhang, 2012). Begley e Fischer (1998) acrescentam que, se houver uma informação negativa, a empresa pode temer uma queda no preço das ações, decorrentes da divulgação imediata. Este fator pode levar a empresa a atrasar a divulgação de suas demonstrações financeiras.

De acordo com Afify (2009) e Abidin e Ahmad-Zaluki (2012), um dos fatores que influenciam no prazo de divulgação das demonstrações financeiras é a auditoria independente, sendo que o trabalho da auditoria é o que determina o prazo para divulgação das demonstrações financeiras.

Outro aspecto que pode influenciar no prazo de publicação das demonstrações financeiras é a existência de um comitê de auditoria. Há observações de que características do comitê de auditoria, como a quantidade de membros, o número de membros independentes e com expertise em contabilidade e finanças, podem influenciar no prazo de publicação das demonstrações financeiras. Quanto mais eficaz for o comitê de auditoria, com observância a suas características, menor será o prazo de publicação das demonstrações financeiras (Ika \& Ghazali, 2012; Song \& Windram, 2004; Pucheta-Martínez \& Fuentes, 2007).

Características das empresas, tais como indicadores econômicos financeiros (Ika \& Ghazali, 2012); tamanho da empresa (Al-Ajmi, 2008; Alkhatib \& Marji, 2012), setor de atuação (Ika \& Ghazali, 2012); e o nível de governança corporativa (Kirch, Lima \& Terra, 2012) também afetam o prazo de publicação das demonstrações financeiras.

O prazo de publicação das demonstrações financeiras pode ainda ser influenciado por características da auditoria independente, como o tamanho da firma de auditoria (Afify, 2009; Ahmed, 2003) e os honorários de não auditoria (Mironiuc, Chersan \& Robu, 2013; Ahadiat, 2011). Empresas de auditoria de grande porte, por possuírem incentivos maiores para a finalização do trabalho de auditoria, contribuem para a redução do tempo de publicação das demonstrações financeiras (Afify, 2009). Quanto ao serviço de não auditoria, quando estes são valores altos, podem reduzir a independência da auditoria, bem como apresentar baixo nível de transparência de informação financeira, interferindo no prazo de publicação das demonstrações financeiras (Ahadiat, 2011; Mironiuc et al., 2013).

Diante do contexto abordado, tem-se a seguinte questão de pesquisa: Qual a relação entre as características da empresa, do comitê de auditoria e do auditor independente com o prazo de publicação das demonstrações financeiras das empresas listadas na BM\&FBOVESPA? Com o propósito de responder a essa questão, o objetivo do estudo é verificar a relação entre as características da empresa, do comitê de auditoria e do auditor independente com o prazo de publicação das demonstrações financeiras das empresas listadas na BM\&FBOVESPA.

Por meio da pesquisa realizada, verificou-se que estudos internacionais analisaram a relação entre a auditoria e a pontualidade das demonstrações financeiras, tais como Healy e Palepu (2001), Ahmed (2003), Al-Ajmi (2008), Afify (2009), Abidin e Ahmad-Zaluki (2012), Alkhatib e Marji (2012). Outros es- 
tudos verificaram o reflexo do comitê de auditoria na qualidade das demonstrações financeiras (Pucheta-Martinez \& Fuentes, 2007) e a relação da eficácia do comitê de auditoria com a pontualidade das demonstrações financeiras (Ika \& Ghazali, 2012). No Brasil, não foram encontrados estudos que verificassem a relação entre a auditoria independente e a data de publicação das demonstrações financeiras. Além disso, tais estudos contribuem na identificação dos fatores que afetam o prazo de divulgação das demonstrações financeiras, auxiliando as empresas no gerenciamento deste prazo, na tentativa de melhorá-los, devido a sua importância para os tomadores de decisão e para o mercado de ações.

\section{Prazo de Divulgação das Demonstrações Financeiras}

As empresas divulgam suas informações por meio de demonstrações financeiras, notas explicativas, pareceres, entre outros (Healy \& Palepu, 2001). A divulgação de informações contábeis demonstra o desempenho operacional da empresa, auxiliando na análise e na tomada de decisão dos diferentes stakeholders (Falcão, 1995).

O prazo de divulgação das demonstrações financeiras das empresas é considerado uma característica qualitativa importante. As informações precisam ser disponibilizadas para os usuários o mais rápido possível, para que possam utilizá-las para a tomada de decisão (Ahmed, 2003).

Sengupta (2004) destaca que a estratégia para uma ótima divulgação é determinada pelos seus custos e benefícios. É por meio da avaliação desses custos e benefícios que os gestores das empresas decidem sobre a natureza, o conteúdo das informações, a data de divulgação, o meio de divulgação, o local, entre outros. De acordo com o CPC 00 (Pronunciamento Técnico CPC 00, 2011), o processo de elaboração e divulgação das informações contábeis envolve custos, e é importante que tais custos sejam justificados pelos benefícios gerados pela divulgação da informação.

Os gestores precisam definir a data de divulgação das demonstrações financeiras, observando se os benefícios desta divulgação mais rápida superam os custos gerados nessa ação (Sengupta, 2004; Kirch, Lima \& Terra, 2012). Kirch et al. (2012) acrescentam que os custos e benefícios a serem analisados correspondem àqueles relacionados às características da empresa, ao ambiente competitivo e ao conteúdo das demonstrações financeiras. Destacam-se como características as relacionadas à complexidade das operações ou da contabilidade, custos de processos, custos de propriedade e governança corporativa, as quais podem influenciar a data de divulgação das demonstrações financeiras.

Kirch et al. (2012) supõem que empresas com melhores práticas de governança corporativa, que fazem parte dos segmentos especiais de listagem, como Nível 1, Nível 2 e Novo Mercado da Bolsa de Valores, Mercadorias e Futuros de São Paulo (BM\&FBOVESPA), e, ainda, aquelas que são mais negociadas no mercado de ações, tendem a divulgar suas demonstrações financeiras com maior rapidez.

Como um dos objetivos das demonstrações financeiras é fornecer informações para os usuários, para auxiliá-los na tomada de decisão, estas precisam ser disponibilizadas em um curto período de tempo após o encerramento do exercício, para não perderem seu valor. É neste sentido que o prazo de divulgação das demonstrações financeiras é reconhecido pelos profissionais da área contábil, usuários, agências reguladoras, entre outros, como uma característica fundamental para a contabilidade (Al-Ajmi, 2008).

Al-Ajmi (2008) destaca, ainda, que as grandes empresas, por possuírem recursos e sofrerem pressão política por partes interessadas, tendem a divulgar suas demonstrações financeiras em menor tempo. Além disso, boas e más notícias são fatores que também podem afetar o prazo de divulgação das informações, entendendo-se que divulgações antecipadas sinalizam notícias positivas sobre o desempenho das empresas, e negativas quando as divulgações das demonstrações financeiras são postergadas. Ainda neste sentido, Iyoha (2012) descreve que a busca de divulgação das demonstrações financeiras em tempo hábil é resultante da crescente necessidade de informações das partes interessadas. Nesse contexto, divulgar uma boa notícia mais rapidamente é mais natural do que demonstrar uma má notícia, a qual pode causar efeitos sobre o preço das ações e outros indicadores da empresa (Iyoha, 2012). 
Afify (2009) destaca também que o prazo de divulgação das demonstrações contábeis tem reflexos do trabalho da auditoria independente, pois tais demonstrações são divulgadas após a finalização da revisão do auditor. Iyoha (2012) expõe que, quando um auditor percebe falha, probabilidade de litígio, fraude financeira, ele desenvolverá o trabalho com muito mais cuidado e cautela, acarretando uma demora para a divulgação das demonstrações financeiras.

\section{Construção das Hipóteses}

A construção das hipóteses relacionadas ao prazo de divulgação das demonstrações financeiras foi efetuada considerando-se variáveis agrupadas em três dimensões: da empresa, do comitê de auditoria; e de auditoria independente.

\section{1 Características da empresa}

Para compor as características da empresa, utilizou-se de indicadores financeiros e econômicos (endividamento, liquidez corrente e retorno sobre o ativo), tamanho, setor de atuação e nível de governança corporativa das empresas, com o intuito de verificar se estes influenciam no prazo de publicação das demonstrações financeiras.

Quanto ao indicador de rentabilidade, este é utilizado para avaliar o lucro gerado pela empresa (Alkhatib \& Marji, 2012). As empresas têm a tendência de divulgar suas demonstrações financeiras antecipadamente quando existem boas notícias (lucros) e tendem a postergar a divulgação quando há más notícias (prejuízos) (Iyoha, 2012). No estudo de Ika e Ghazali (2012) verificou-se que os indicadores "endividamento", "liquidez corrente" e "retorno sobre o ativo" influenciaram a pontualidade dos relatórios, aumentando o tempo de publicação das demonstrações financeiras.

No que se refere ao tamanho da empresa, pressupõe-se que quanto maior a empresa, maior é a procura por uma auditoria de alta qualidade, considerando neste caso, as grandes empresas de auditoria, pelo conjunto de recursos que reúnem para a realização do trabalho. As grandes empresas, por possuírem recursos e sofrerem pressão política das partes interessadas, tendem a divulgar suas informações antecipadamente (Al-Ajmi, 2008). Alkhatib e Marji (2012) destacam que o tamanho da empresa é uma das variáveis mais utilizadas para determinar o impacto na pontualidade das demonstrações financeiras. No entanto, no estudo de Ika e Ghazali (2012), o tamanho da empresa não teve relação significativa para influenciar na pontualidade dos relatórios.

Quanto ao setor de atuação das empresas, entende-se que o contexto de cada setor pode ter reflexos no prazo de publicação das demonstrações financeiras. No estudo de Ika e Ghazali (2012), verificou-se que o setor influencia o prazo de publicação das demonstrações financeiras ao efetuar uma análise com indústrias e prestadoras de serviços. Os autores concluem que as indústrias estão mais propensas a liberar tardiamente as demonstrações contábeis, enquanto as prestadoras de serviço, por não apresentarem inventário de estoque, podem divulgar suas informações em menos tempo, comparativamente às indústrias.

No Brasil, empresas listadas na BM\&FBOVESPA e que fazem parte de níveis de governança corporativa, comprometem-se a atender a um conjunto de regras, no que se refere aos investidores e à divulgação oportuna das demonstrações financeiras. Entende-se que empresas que compõem níveis de governança corporativa tendem a divulgar suas informações em menor tempo (Kirch et al., 2012).

Empresas organizacionalmente complexas, representadas pela quantidade de subsidiárias da empresa, possuem dificuldade de monitoramento da gestão, necessitando de maior trabalho realizado pela auditoria (Bushman, Chen, Engel \& Smith, 2004), o que, por sua vez, pode elevar o prazo de publicação das demonstrações financeiras.

Diante das exposições acerca das variáveis utilizadas no estudo, apresenta-se a primeira hipótese a ser verificada: 
H1: Há uma relação significativa entre indicadores econômico-financeiros, tamanho, setor de atuação, governança corporativa e a quantidade de subsidiárias das empresas com o prazo de publicação das demonstrações financeiras.

\subsection{Características do Comitê de Auditoria}

O comitê de auditoria tem a responsabilidade de supervisionar os processos internos e assegurar a integridade e a efetividade destes para a geração das demonstrações financeiras, e, dessa forma, garantir a sua qualidade, contemplando o objetivo de proteger os acionistas e outras partes interessadas (IBGC, 2009).

O estudo de Ika e Ghazali (2012) constatou que a eficácia do comitê de auditoria é um fator importante que influencia a pontualidade da divulgação dos relatórios financeiros. Para medir a eficácia, foram analisados, de forma conjunta, a independência dos membros do comitê e a sua formação na área contábil, auditoria ou finanças, tamanho do comitê de auditoria. Analisaram ainda se divulgavam informações voluntariamente e se realizavam reuniões pelo menos quatro vezes por ano. Para o presente estudo, devido à disponibilidade das informações, utilizaram-se as variáveis independência, tamanho e expertise dos membros do comitê de auditoria.

Em relação à independência, entende-se que o comitê de auditoria terá maior independência e trabalhará de forma mais eficaz se seus membros, na maioria, forem conselheiros externos independentes (Pucheta-Martinez \& Fuentes, 2007). Song e Windram (2004) destacam que há evidências que apoiam a afirmação de que maior número de conselheiros independentes aumenta a eficácia do comitê de auditoria. Vlaminck e Sarens (2012) realizaram estudo na Bélgica, buscando a relação entre as características do comitê de auditoria e a qualidade das demonstrações financeiras. Os autores encontraram uma relação positiva entre a independência do comitê de auditoria e a qualidade das demonstrações financeiras.

Quanto à formação na área contábil, auditoria e finanças, no estudo de Ika e Ghazali (2012), foi estabelecido como critério, para calcular a eficiência do comitê de auditoria, ter pelo menos um membro do comitê que possua formação e experiência em contabilidade ou finanças. Dezoort, Hermanson e Houston (2003) ressaltam que o papel fundamental do comitê de auditoria é supervisionar os processos para garantir a integridade dos relatórios financeiros para as partes interessadas e que membros com maior experiência oferecem maior apoio ao auditor, evidenciando, assim, a importância dos membros do comitê possuirem experiência financeira.

Defond, Hann e Hu (2005) verificaram a reação do mercado quando são nomeados novos membros do comitê de auditoria, constatando que o mercado responde positivamente apenas quando os membros têm conhecimento em auditoria e especialidade contábil. Abernathy, Herrmann, Kang e Krishnan (2013) mencionam que, na medida em que a experiência financeira dos membros do comitê de auditoria aumenta, uma qualidade superior é esperada nos relatórios financeiros.

No que se refere ao tamanho do comitê de auditoria, considera-se que quanto maior este for, menor será a pressão da gestão da empresa sobre o comitê de auditoria quanto à resistência aos ajustes propostos pela auditoria independente. Neste sentido, o número de membros do comitê de auditoria pode influenciar a aceitação ou rejeição de ajustes propostos pelo auditor (Pucheta-Martinez \& Fuentes, 2007), o que pode afetar, dessa forma, o prazo de divulgação das demonstrações financeiras.

Krishnan (2005) estudou a associação da qualidade do comitê de auditoria com o controle interno das empresas. A qualidade do comitê de auditoria é medida em três dimensões: o seu tamanho; a sua independência; e a expertise dos membros. Os problemas de controle interno foram observados em dois aspectos, condições relatáveis e fraquezas materiais. A amostra foi composta por 128 empresas, no período de 1994 a 2000, que tiveram a troca de auditores, observadas no relatório Form 8-K, disponível na SEC. Nesses relatórios foram observados os problemas de controles internos. Os resultados apontam que os comitês de auditoria independentes e com expertise financeira são significativamente menos prováveis de serem associados com incidência de problemas de controle interno, constatados para ambos os níveis de problemas de controle interno. 
Com base no estudo de Krishnan (2005), percebe-se que as características do comitê de auditoria mencionadas afetam a qualidade dos controles internos, e que estes, revestidos de maior qualidade, podem refletir no tempo de trabalho do auditor. Um menor tempo despendido nos trabalhos de auditoria, em decorrência de bons controles internos, pode afetar no prazo de divulgação das demonstrações financeiras.

Considerando a exposição acerca das características independência, expertise e tamanho do comitê de auditoria, tem-se a segunda hipótese do estudo:

H2: Há uma relação significativa entre as características do comitê de auditoria, como independência, expertise e tamanho, com o prazo de publicação das demonstrações financeiras.

\subsection{Características relacionadas à Auditoria Independente}

Pesquisas evidenciam que as grandes firmas de auditoria proporcionam serviços de maior qualidade (Al-Ajmi, 2008). Afify (2009) acrescenta que as maiores empresas de auditoria possuem maior incentivo para finalizar o trabalho de auditoria em menor prazo, com o objetivo de manter sua reputação, caso contrário, podem perder a recolocação como auditor da empresa no próximo ano. No estudo de Ahmed (2003), verificou-se que o tipo de auditor reduz o tempo de divulgação das demonstrações financeiras.

Outra variável refere-se aos serviços de não auditoria. No estudo de Mironiuc e Robu (2012), evidenciou-se que as empresas que pagam valores altos para serviços de não auditoria têm um baixo nível de transparência de informação financeira (Mironiuc, Chersan \& Robu, 2013). Ahadiat (2011) constatou que pode ocorrer redução na independência da auditoria quando são pagos valores altos de serviços de não auditoria. O grupo de empresas com parecer sem ressalva apresentaram maiores médias de honorários de não auditoria do que as empresas com ressalva em seus pareceres.

De acordo com Solomon, Reckers e Lowe (2005), os investidores possuem mais confiança nas informações financeiras auditadas por empresas que prestam poucos serviços de não auditoria, em decorrência de que afeta a independência do auditor e a qualidade das demonstrações financeiras.

Diante do exposto, tem-se a enunciação das seguintes hipóteses:

H3: Há uma relação significativa entre as empresas auditadas por Big Four com o prazo de publicação das demonstrações financeiras.

H4: Há uma relação significativa entre os honorários de não auditoria com o prazo de publicação das demonstrações financeiras.

\section{Procedimentos Metodológicos}

O estudo classifica-se como descritivo, documental e com abordagem quantitativa. A população compreendeu as empresas listadas na Bolsa de Valores, Mercadorias e Futuros de São Paulo (BM\&FBOVESPA). Para definição da amostra, inicialmente selecionaram-se as empresas que possuíam comitê de auditoria nos anos de 2010, 2011 e 2012. Depois foram verificadas se todas as empresas possuíam as informações necessárias diante das variáveis utilizadas no estudo. Assim, de 92 empresas pré-selecionadas, após exclusão daquelas sem as informações necessárias, a amostra final ficou composta por 64 empresas para cada ano de análise.

Para demonstrar as variáveis e a sua forma de operacionalização, elaborou-se um constructo. Martins e Theóphilo (2007, p.35) descrevem que "para explorar empiricamente um conceito teórico, o pesquisador precisa traduzir a assertiva genérica do conceito em uma relação com o mundo real, baseada em variáveis e fenômenos observáveis e mensuráveis, ou seja, elaborar (construir) um constructo e operacionalizá-lo". O constructo desta pesquisa está apresentado no Quadro 1. 


\begin{tabular}{|c|c|c|c|c|}
\hline Dimensão & Variável & Descrição & Coleta & Autores \\
\hline \multicolumn{5}{|c|}{ Variável dependente } \\
\hline $\begin{array}{l}\text { Prazo de } \\
\text { publicação das } \\
\text { demonstrações } \\
\text { financeiras }\end{array}$ & $\begin{array}{l}\text { Prazo de } \\
\text { publicação das } \\
\text { demonstrações } \\
\text { financeiras (PRZ) }\end{array}$ & $\begin{array}{l}\text { Número de dias entre o último } \\
\text { dia do exercício social até a data } \\
\text { de publicação das demonstrações } \\
\text { financeiras. }\end{array}$ & $\begin{array}{l}\text { Sítio da } \\
\text { BM\&FBOVESPA }\end{array}$ & $\begin{array}{l}\text { Ahmed (2003), Pucheta- } \\
\text { Martinez e Fuentes (2007), } \\
\text { Afify (2009), Ika e Ghazali } \\
\text { (2012). }\end{array}$ \\
\hline \multicolumn{5}{|c|}{ Variáveis independentes } \\
\hline \multirow{7}{*}{$\begin{array}{l}\text { Empresa } \\
\text { auditada }\end{array}$} & $\begin{array}{l}\text { Endividamento } \\
\text { (END) }\end{array}$ & $\begin{array}{l}\text { Relação entre o passivo total } \\
\text { sobre o ativo total. }\end{array}$ & Economática $®$ & $\begin{array}{l}\text { Alkhatib e Marji (2012), lyoha } \\
\text { (2012), Ika e Ghazali (2012). }\end{array}$ \\
\hline & $\begin{array}{l}\text { Retorno sobre o } \\
\text { ativo (ROA) }\end{array}$ & Lucro líquido sobre o ativo total. & Economática® & $\begin{array}{l}\text { Alkhatib e Marji (2012), lyoha } \\
\text { (2012), Ika e Ghazali (2012). }\end{array}$ \\
\hline & $\begin{array}{l}\text { Liquidez corrente } \\
\text { da empresa (LIQ) }\end{array}$ & $\begin{array}{l}\text { Relação entre o ativo circulante e } \\
\text { o passivo circulante. }\end{array}$ & Economática® & $\begin{array}{l}\text { Alkhatib e Marji (2012), lyoha } \\
\text { (2012), Ika e Ghazali (2012). }\end{array}$ \\
\hline & $\begin{array}{l}\text { Tamanho da } \\
\text { empresa (TAM) }\end{array}$ & $\begin{array}{l}\text { Logaritmo natural dos ativos } \\
\text { totais das empresas. }\end{array}$ & 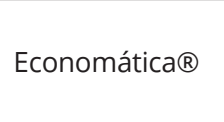 & $\begin{array}{l}\text { Al-Ajmi, (2008), Alkhatib e } \\
\text { Marji (2012), Ika e Ghazali } \\
\text { (2012). }\end{array}$ \\
\hline & $\begin{array}{l}\text { Setor de atuação } \\
\text { (SET) }\end{array}$ & $\begin{array}{l}\text { Setor de atuação da empresa. } \\
\text { Variáveis dummies para cada } \\
\text { setor. }\end{array}$ & $\begin{array}{l}\text { Sítio da } \\
\text { BM\&FBOVESPA }\end{array}$ & Ika e Ghazali (2012). \\
\hline & $\begin{array}{l}\text { Governança } \\
\text { Corporativa (GC) }\end{array}$ & $\begin{array}{l}\text { Variável dummy: } 1 \text { se faz parte do } \\
\text { nível de governança corporativa e } \\
0 \text { caso contrário. }\end{array}$ & $\begin{array}{l}\text { Sítio da } \\
\text { BM\&FBOVESPA }\end{array}$ & Kirch et al. (2012). \\
\hline & Subsidiárias (Subs) & $\begin{array}{l}\text { Número de subsidiárias da } \\
\text { empresa. }\end{array}$ & $\begin{array}{l}\text { Formulário de } \\
\text { Referência - } \\
\text { Item } 8.1\end{array}$ & Bushman et al. (2004). \\
\hline \multirow{3}{*}{$\begin{array}{l}\text { Comitê de } \\
\text { auditoria }\end{array}$} & $\begin{array}{l}\text { Independência } \\
\text { (IND) }\end{array}$ & $\begin{array}{l}\text { Relação entre o número de } \\
\text { membros independentes e o } \\
\text { total de membros do comitê de } \\
\text { auditoria. }\end{array}$ & $\begin{array}{l}\text { Formulário de } \\
\text { Referência - } \\
\text { Item } 12.7\end{array}$ & $\begin{array}{l}\text { Song e Windram (2004), } \\
\text { Pucheta-Martinez e Fuentes } \\
\text { (2007), Ika e Ghazali (2012). }\end{array}$ \\
\hline & Tamanho (TCA) & $\begin{array}{l}\text { Quantidade de membros no } \\
\text { comitê de auditoria. }\end{array}$ & $\begin{array}{l}\text { Formulário de } \\
\text { Referência - } \\
\text { Item } 12.7\end{array}$ & $\begin{array}{l}\text { Pucheta-Martinez e Fuentes } \\
\text { (2007), Ika e Ghazali (2012). }\end{array}$ \\
\hline & Expertise (EXP) & $\begin{array}{l}\text { Relação entre o número de } \\
\text { membros do comitê de auditoria } \\
\text { com formação em contabilidade, } \\
\text { auditoria e finanças e o total de } \\
\text { membros do comitê de auditoria. }\end{array}$ & $\begin{array}{l}\text { Formulário de } \\
\text { Referência - } \\
\text { Item } 12.7\end{array}$ & Ika e Ghazali (2012). \\
\hline \multirow{2}{*}{$\begin{array}{l}\text { Auditoria } \\
\text { Independente }\end{array}$} & Big_Four (BIG) & $\begin{array}{l}\text { Variável dummy em que } 1 \text { igual a } \\
\text { Big Four, senão } 0 .\end{array}$ & $\begin{array}{l}\text { Formulário de } \\
\text { Referência - } \\
\text { Item } 2.1\end{array}$ & $\begin{array}{l}\text { Ahmed (2003), Afify (2009), } \\
\text { Ika e Ghazali (2012). }\end{array}$ \\
\hline & $\begin{array}{l}\text { Honorários de } \\
\text { não auditoria } \\
\text { (HNA) }\end{array}$ & $\begin{array}{l}\text { Logaritmo natural dos honorários } \\
\text { pagos por serviços de não } \\
\text { auditoria. }\end{array}$ & $\begin{array}{l}\text { Formulário de } \\
\text { Referência - } \\
\text { Item } 2.1\end{array}$ & $\begin{array}{l}\text { Mironiuc et al. (2013), } \\
\text { Mironiuc e Robu (2012), } \\
\text { Ahadiat (2011). }\end{array}$ \\
\hline
\end{tabular}

Figura 1. Variáveis do estudo

Fonte: elaborado pelos autores.

A coleta de dados foi possibilitada pela busca secundária dos dados necessários ao estudo por meio da base de dados Economática ${ }^{\circledR}$, do Formulário de Referência e do sítio da BM\&FBOVESPA.

Primeiramente, buscaram-se na Economática ${ }^{\oplus}$ as variáveis relacionadas com os indicadores econômico-financeiros e com o tamanho das empresas. Utilizaram-se dos dados do Formulário de Referência e do sítio da BM\&FBOVESPA para explorar as demais variáveis, como setor de atividade; governança corporativa; quantidade de subsidiárias; data de publicação das demonstrações financeiras; tipo de auditoria; honorários de não auditoria; e características do comitê de auditoria. 
O período de análise compreendeu os anos de 2010 a 2012 e a coleta dos dados ocorreu no mês de dezembro de 2013. Os dados coletados foram tabulados e compilados em planilha eletrônica e, posteriormente, calculados com a utilização do software SPSS ${ }^{\circledR}$ versão 20.0. Para a análise dos dados, utilizaram-se a estatística descritiva e a análise de regressão linear múltipla.

\section{Descrição e Análise dos Resultados}

Apresentam-se nesta seção a descrição e a análise dos principais resultados do presente estudo, quanto à relação entre as características da empresa, do comitê de auditoria e do auditor independente com o prazo de publicação das demonstrações financeiras das empresas listadas na BM\&FBOVESPA.

Na Tabela 1, é apresentada a análise estatística descritiva das variáveis utilizadas no estudo.

Tabela 1

Estatística descritiva das variáveis utilizadas no estudo

\begin{tabular}{lrrrrc}
\hline \multicolumn{1}{c}{ Variáveis } & Mínimo & Máximo & Média & Mediana & Desvio Padrão \\
\hline Prazo de publicação das DC & 28,0 & 675,0 & 95,328 & 83,000 & 74,9394 \\
\hline Endividamento (END) & 0,000 & 64,705 & 23,36307 & 25,78862 & 19,022590 \\
\hline Retorno sobre o ativo (ROA) & 0,001 & 1,993 & 0,06794 & 0,03557 & 0,164842 \\
\hline Liquidez corrente (LIQ) & 0,000 & 6,338 & 1,44020 & 1,37841 & 1,064448 \\
\hline Tamanho da empresa (TAM) & 11,153 & 20,679 & 16,10522 & 16,08428 & 1,565925 \\
\hline Independência (IND) & 0,0 & 3,0 & 0,026 & 0,000 & 0,2270 \\
\hline Tamanho do comitê (TCA) & 1,0 & 9,0 & 3,557 & 3,000 & 1,2478 \\
\hline Expertise (EXP) & 0,000 & 1,000 & 0,19940 & 0,00000 & 0,244641 \\
\hline Honorários de não auditoria (HNA) & 0,000 & 15,222 & 3,02605 & 0,00000 & 5,241899 \\
\hline Subsidiárias (Subs) & 0,000 & 147 & 12,22 & 6 & 19,918 \\
\hline
\end{tabular}

Fonte: dados da pesquisa.

Inicialmente, tem-se uma análise descritiva da variável dependente, que é o prazo de publicação das demonstrações contábeis. Na Tabela 1, verifica-se que a mediana da amostra selecionada corresponde a 83 dias. Isto indica que, na amostra selecionada, 50\% das empresas levam até 83 dias para publicar suas demonstrações, sendo que o menor período apresentado é de 28 dias. Por outro lado, os outros $50 \%$ das empresas demoram 83 dias ou mais para divulgarem os demonstrativos, em que o maior prazo apresentado durante todo o período selecionado equivale a 675 dias. Considerando que no Art. 132 da Lei no 6.404 (1976) há estabelecido o prazo de 30 dias antes da Assembleia Geral Ordinária (AGO) para que as demonstrações financeiras estejam à disposição dos acionistas e, sendo o dia 30 de abril do ano subsequente a data limite para a realização da AGO, subentende-se que 31 de março do ano subsequente é o prazo limite para fechamento das demonstrações financeiras (Conselho Federal de Contabilidade, 2015). Diante dos resultados encontrados, $50 \%$ das empresas realizam o fechamento das suas demonstrações financeiras dentro do prazo estabelecido.

Quanto ao endividamento das empresas estudadas, percebe-se que há, no mínimo, uma empresa durante os três anos cujo endividamento é nulo. $\mathrm{O}$ retorno sobre o ativo é um importante indicador, que possibilita verificar quanto que os investimentos e aplicações da empresa (ativo) geram de rentabilidade (lucro). A Tabela 1 indica que a menor rentabilidade apresentada é de 0,001 e o máximo é de 1,993, em que, para cada $R \$ 1,00$ de ativo da empresa, há um rendimento de $\mathrm{R} \$ 1,993$ a seus investidores. Por outro lado, percebe-se que em média as empresas possuem rentabilidade de 0,067 , com desvio padrão de 0,164 . Dessa forma, identifica-se que a média da rentabilidade apresentada pelas empresas oscila entre R\$-0,097 e R \$0,231. Conforme Alkhatib e Marji (2012), as empresas tendem a publicar suas demonstrações mais rapidamente quando estas apresentam resultado positivo, assim como levam maior tempo para publicá-las os mesmos, caso o resultado seja negativo (Iyoha, 2012). 
Para analisar a relação entre o ativo e o passivo circulantes das empresas, utiliza-se o indicador de liquidez corrente. Percebe-se que nos três anos analisados, o índice de liquidez máximo é de R\$6,338. Também é possível identificar que a média apresentada pelas empresas é de, aproximadamente, $R \$ 1,44$, o que demonstra que há capital disponível para liquidar as obrigações de curto prazo.

Analisando o tamanho da empresa, têm-se o valor mínimo do ativo das empresas estudadas equivalente a 11,15 e o valor máximo equivalente a 20,67, em que estes valores correspondem ao logaritmo natural do ativo total da empresa. A média das empresas analisadas no presente trabalho é de 16,10, com desvio padrão de 1,56. De acordo com Al-Ajmi (2008), o tamanho da empresa influencia a agilidade para publicação das demonstrações contábeis, de maneira que quanto maior a empresa, menor o prazo de publicação de suas demonstrações.

O comitê de auditoria é um órgão delegado pelo conselho de administração da empresa para auxiliar a empresa na governança corporativa e, consequentemente, na qualidade das informações contábeis apresentadas (IBGC, 2009). Entre as características do comitê de auditoria, destacam-se a independência, o tamanho e a expertise dos membros.

Verifica-se, na Tabela 1, que, nos três anos avaliados, há pelo menos uma empresa que não possui membros com independência e, por outro lado, há pelo menos uma empresa cujos membros são todos independentes, em que a média de membros independentes nos comitês analisados é de 0,02 . Esse fato se repete para a característica expertise dos membros do comitê, em se tratando de valores mínimos e máximos, porém a média de membros com expertise é de 0,19 .

O tamanho do comitê de auditoria também é considerado uma característica importante, em que as empresas devem constituir comitês com a quantidade de membros (tamanho) de acordo com sua necessidade. Na Tabela 1, identifica-se que as empresas da amostra possuem comitês de auditoria com um tamanho mínimo de 1 membro e máximo de 9 membros, sendo que $50 \%$ da amostra apresentam comitês com 1 a 3 membros e $50 \%$ possuem de 3 a 9 membros em sua composição.

Quanto à firma de auditoria, Mironiuc et al. (2013) mencionam que os honorários de não auditoria interferem na qualidade das demonstrações contábeis, comprometendo a transparência e fidedignidade destas. Ahadiat (2011) identificou em sua pesquisa, que os grupos de empresas com parecer sem ressalva apresentavam maior média de honorários de não auditoria em relação ao grupo de empresas que possuíam parecer com ressalva. Analisando a Tabela 1, percebe-se que no mínimo 50\% das empresas não contratavam serviços de não auditoria - este valor é percebido na mediana que comporta valor igual a $\mathrm{R} \$ 0,00$. Ainda, quanto ao número de subsidiárias das empresas, que representa a complexidade organizacional, verificou-se que as empresas da amostra possuem no máximo 147 subsidiárias, e algumas não apresentam nenhuma.

Efetuada uma análise descritiva das variáveis utilizadas, a seguir apresentam-se os testes referentes à distribuição dos dados, importantes para a utilização da técnica de regressão linear múltipla. Assim, na Tabela 2, é apresentado o resultado dos testes de aleatoriedade, normalidade, homocedasticidade e multicolinearidade dos dados, efetuados mediante aplicação dos testes de Durbin-Watson, Shapiro-Wilk e Levene.

Tabela 2

\section{Análise dos pressupostos da regressão linear múltipla}

\begin{tabular}{|c|c|c|}
\hline Pressupostos & Testes & Hipótese \\
\hline Aleatoriedade & $\begin{array}{l}\text { Durbin-Watson: } \\
\text { Estatística DW }=2,0651 \\
\text { Valor-p }=1,0000 \\
\text { Autocorrelação dos resíduos }=-0,0326\end{array}$ & $\begin{array}{l}\text { Inexiste autocorrelação de primeira ordem } \\
\text { entre os resíduos. }\end{array}$ \\
\hline Normalidade & $\begin{array}{l}\text { Shapiro-Wilk: } \\
\text { Estatística SW =0,7407 } \\
\text { Valor-p }=0,0000\end{array}$ & A distribuição dos resíduos é normal. \\
\hline Homocedasticidade & $\begin{array}{l}\text { Levene: } \\
\text { Estatística F=4,4752 } \\
\text { Valor-p = 0,0357 }\end{array}$ & A variância dos erros é uniforme. \\
\hline
\end{tabular}

Fonte: dados da pesquisa. 
Aplicou-se o teste Durbin-Watson para atender ao pressuposto da aleatoriedade. Segundo Marôco (2011), esse teste deve apresentar um valor próximo de 2 para demonstrar a inexistência de autocorrelação entre os resíduos. Dessa forma, observa-se, na Tabela 2, o atendimento a este pressuposto por apresentar valor igual a 2,0651.

Por meio do teste Shapiro-Wilk(SW), foi testada a normalidade dos dados. O teste compara a "distribuição de frequência acumulada de um conjunto de valores observados da amostra com uma distribuição esperada ou teórica" (Fávero, Belfiore, Silva \& Chan, 2009, p. 112). No presente estudo, o teste SW apresentou-se significante ao nível de $1 \%$, o que corresponde que a distribuição dos resíduos é normal.

Para análise de homocedasticidade, utilizou-se o teste de Levene. Conforme Marôco (2011), o teste de Levene é um dos testes mais utilizados para verificar se as variâncias populacionais são homogêneas, ou seja, iguais. Observa-se que o teste de Levene não foi significativo, o que significa que a variância dos erros é uniforme. Após atender aos pressupostos referentes à distribuição dos dados, a Tabela 3 demonstra o resumo do modelo da regressão linear múltipla.

Tabela 3

\section{Resumo do modelo da regressão linear múltipla}

\begin{tabular}{cccccc}
\hline Modelo & $\mathbf{R}$ & $\mathbf{R}^{2}$ & $\mathbf{R}^{2}$ ajustado & Erro padrão da estimativa & Durbin-Watson \\
\hline 1 & 0,429 & 0,184 & 0,082 & 71,974 & 2,065 \\
\hline
\end{tabular}

Fonte: dados da pesquisa.

Na Tabela 3 é possível perceber se o modelo utilizado foi eficaz em prever a influência das variáveis sobre o prazo de publicação das demonstrações contábeis. O Coeficiente de Correlação (R), conforme Corrar, Paulo e Dias Filho (2009), indica o nível de associação existente entre as variáveis. Nesse sentido, o valor de 0,429 representa uma associação de $42,9 \%$ entre as variáveis utilizadas no presente estudo.

O Coeficiente de Determinação $\left(\mathrm{R}^{2}\right)$ apresentou um poder explicativo das variáveis independentes de 18,40\%. Entretanto, o teste de Durbin-Watson não demonstrou problema de autocorrelação dos resíduos. Conforme Marôco (2011), o resultado do DW deve estar próximo de 2, porém não abaixo de 1,70 e nem acima de 2,2. Assim, verifica-se que o modelo não teve problemas de autocorrelação dos resíduos, pois seu valor é de 2,065 .

Em seguida, apresenta-se a Tabela 4 que demonstra a análise da variância.

Tabela 4

Análise da variância dos dados

\begin{tabular}{clccccc}
\hline \multicolumn{1}{l}{ Modelo } & Soma dos Quadrados & DF & Quadrado Médio & F & Sig. \\
\hline \multirow{2}{*}{1} & Regressão & 197002,651 & 21 & 9381,079 & 1,811 & 0,021 \\
\cline { 2 - 7 } & Resíduos & 875459,108 & 169 & 5180,231 & & \\
\cline { 2 - 7 } & Total & 1072461,759 & 190 & & & \\
\hline
\end{tabular}

Fonte: dados da pesquisa.

Observa-se na Tabela 4 que os resultados apresentados pela análise de variância dos dados, por meio do teste $\mathrm{F}$, demonstram que as variáveis independentes utilizadas no modelo apresentam-se significativas ao nível de $5 \%$, para que em seguida se identifiquem quais destas variáveis influenciam no prazo de publicação das demonstrações financeiras, como exposto na Tabela 5. 
Tabela 5

\section{Análise das variáveis utilizadas no estudo}

\begin{tabular}{|c|c|c|c|c|c|}
\hline \multirow[t]{2}{*}{ Modelo } & \multicolumn{2}{|c|}{ Coeficientes não padronizados } & \multirow{2}{*}{$\begin{array}{c}\begin{array}{c}\text { Coeficientes } \\
\text { padronizados }\end{array} \\
\text { Beta }\end{array}$} & \multirow[t]{2}{*}{$\mathbf{T}$} & \multirow[t]{2}{*}{ Sig. } \\
\hline & B & Modelo Padrão & & & \\
\hline Prazo public. das DC (Constante) & 110,770 & 89,261 & & 1,241 & 0,216 \\
\hline \multicolumn{6}{|c|}{ Características da empresa } \\
\hline Endividamento (END) & 1,143 & 0,497 & 0,290 & 2,302 & $0,023^{*}$ \\
\hline Retorno sobre o ativo (ROA) & 56,205 & 38,100 & 0,124 & 1,475 & 0,142 \\
\hline Liquidez corrente (LIQ) & $-3,587$ & 6,255 & $-0,051$ & $-0,573$ & 0,567 \\
\hline Tamanho da empresa (TAM) & 1,966 & 5,457 & 0,041 & 0,360 & 0,719 \\
\hline Governança Corp. (GC) & 5,179 & 17,248 & 0,025 & 0,300 & 0,764 \\
\hline Subsidiárias (Subs) & 0,218 & 0,312 & 0,058 & 0,700 & 0,485 \\
\hline Consumo cíclico (ConsuCic) & $-12,074$ & 24,311 & $-0,047$ & $-0,497$ & 0,620 \\
\hline Financeiros e outros (Finan) & $-4,711$ & 23,334 & $-0,029$ & $-0,212$ & 0,840 \\
\hline Consumo não cíclico (ConNCic) & 3,976 & 23,121 & 0,016 & 0,172 & 0,864 \\
\hline Construção e transporte (ConsTrans) & $-55,613$ & 24,883 & $-0,232$ & $-2,235$ & $0,027 *$ \\
\hline Utilidade pública (UtilPubl) & $-38,170$ & 36,111 & $-0,089$ & $-1,057$ & 0,292 \\
\hline Materiais básicos (MatBas) & $-34,244$ & 21,308 & $-0,151$ & $-1,607$ & 0,110 \\
\hline Telecomunicações (Telec) & $-38,501$ & 42,386 & $-0,082$ & $-0,908$ & 0,365 \\
\hline Bens industriais (BensIndus) & $-77,441$ & 45,925 & $-0,128$ & $-1,686$ & $0,094 * *$ \\
\hline Petróleo, gás e biocombustív.(Petrol) & $-61,734$ & 52,015 & $-0,102$ & $-1,187$ & 0,237 \\
\hline Tecnologia informação (Teclnform) & $-63,289$ & 36,727 & $-0,147$ & $-1,723$ & $0,087 * *$ \\
\hline \multicolumn{6}{|c|}{ Características do comitê de auditoria } \\
\hline Independência (IND) & 1,325 & 23,474 & 0,004 & 0,056 & 0,955 \\
\hline Tamanho do comitê (TCA) & $-2,009$ & 5,936 & $-0,033$ & $-0,338$ & 0,735 \\
\hline Expertise (EXP) & 19,785 & 24,842 & 0,064 & 0,796 & 0,427 \\
\hline \multicolumn{6}{|c|}{ Características da auditoria independente } \\
\hline Big Four (BIG) & $-68,498$ & 27,160 & $-0,183$ & $-2,522$ & $0,013^{*}$ \\
\hline Honorários de não auditoria (HNA) & 2,826 & 1,080 & 0,195 & 2,618 & $0,010 *$ \\
\hline
\end{tabular}

$\left.{ }^{*}\right)$ Significativo a 5\%; (**) Significativo a $10 \%$.

Fonte: dados da pesquisa.

A análise de significância foi observada ao nível de 5\% ( $p$-value< 0.05 ) e ao nível de $10 \%$ ( $p$-value< 0.10 ). De acordo com os resultados apresentados na Tabela 5 , verifica-se que as características da empresa mostraram-se estatisticamente significantes. O Endividamento (END) e o setor de atuação Construção e Transporte (ConsTrans) mostraram-se estatisticamente significantes ao nível de $5 \%$ e o setor de atuação Bens Industriais (BensIndus) e Tecnologia da Informação (TecInform) apresentaram-se com significância de 10\%.

O Endividamento (END), com um $\beta$ igual a 1,143, possui influência positiva e significante sobre $o$ prazo de publicação das demonstrações financeiras. Dessa forma, quanto maior o endividamento, maior deve ser o prazo de publicação das demonstrações financeiras. De forma contrária, os setores de atuação Construção e Transporte (ConsTrans), Bens Industriais (BensIndus) e Tecnologia da Informação (TecInform), $\operatorname{com} \beta$ igual a -55,613, -77,441 e -63,289, respectivamente, possuem influência negativa e significante sobre o prazo de publicação das demonstrações contábeis. Este resultado demonstra que as empresas desses setores tendem a divulgar em menor tempo as demonstrações financeiras.

Esses resultados convergem com os estudos de Iyoha (2012) e de Ika e Ghazali (2012), em relação à significância encontrada entre o endividamento da empresa e o prazo de publicação, verificando 
que empresas mais endividadas podem dilatar o prazo de publicação das demonstrações financeiras para postergar possíveis efeitos da divulgação do endividamento que a empresa se encontra. No que tange aos setores de atuação, os resultados se alinham aos achados de Ika e Ghazali (2012), no que diz respeito às empresas prestadoras de serviços (tecnologia da informação), ao verificarem que estas, por não apresentarem inventário de estoque, tendem a divulgar informações em menor tempo. Porém, diverge no quesito de empresas com concentração industrial (bens industriais, construção e transporte), pois estas não impactaram no aumento do prazo de publicação das demonstrações financeiras.

Diante dos achados, pode-se aceitar parcial a hipótese 1 de que há uma relação significativa entre indicadores econômico-financeiros, tamanho, setor de atuação, governança corporativa e a quantidade de subsidiárias das empresas com o prazo de publicação das demonstrações financeiras, especificamente quanto ao endividamento e ao setor de atuação.

As características relacionadas ao comitê de auditoria, independência, tamanho e expertise não se mostraram significativas para explicar o prazo de divulgação das demonstrações financeiras. Esta constatação refuta a hipótese 2 de que há uma relação significativa entre as características do comitê de auditoria com o prazo de publicação das demonstrações financeiras. Este resultado diverge dos achados de Ika e Ghazali (2012), que encontraram relação significante entre as características do comitê de auditoria e o prazo de publicação das demonstrações financeiras na Indonésia.

Por fim, verifica-se que as características relacionadas ao auditor independente mostraram relação significante com o prazo de divulgação das demonstrações financeiras. Firmas de auditoria Big Four apresentaram uma relação negativa com o prazo de divulgação das demonstrações financeiras com um $\beta$ de $-68,498$ e significativa a $5 \%$ ( $p$-value $<0.05$ ). Assim, percebe-se que o prazo de divulgação menor ocorre com as empresas auditadas pelas Big Four.

De forma contrária, os honorários de não auditoria apresentaram uma relação positiva, $\operatorname{com} \beta$ de 2,826 e significativa a $5 \%$ (p-value< 0.05 ), ou seja, quanto mais se utiliza de serviços de não auditoria, maior é o prazo de divulgação. Isto pode ser explicado pelo fato de que as empresas que pagam valores altos para serviços de não auditoria têm um baixo nível de transparência de informação financeira (Mironiuc; Chersan \& Robu, 2013).

Estes resultados aceitam a hipótese 3 de que há uma relação significativa entre as empresas auditadas por Big Four com o prazo de publicação das demonstrações financeiras. Este achado converge com os estudos de Ahmed (2003), Al-Ajmi (2008), Afify (2009) e Ika e Ghazali (2012), ao demonstrar que empresas auditadas por Big Four divulgam suas demonstrações financeiras em menor tempo do que as não auditadas por Big Four. Isto decorre do fato de que as grandes firmas de auditoria proporcionam serviços de maior qualidade (Al-Ajmi, 2008), e que as maiores empresas de auditoria possuem maior incentivo para finalizar o trabalho de auditoria em menor prazo, com o objetivo de manter sua reputação (Afify, 2009)

Os resultados ainda confirmam a hipótese 4 , de que há uma relação significativa entre os honorários de não auditoria com o prazo de publicação das demonstrações financeiras.

\section{Conclusão}

O objetivo do presente estudo foi verificar a relação entre as características da empresa, do comitê de auditoria e do auditor independente com o prazo de publicação das demonstrações financeiras das empresas listadas na BM\&FBOVESPA. Para tal, utilizou-se de análise descritiva, documental e quantitativa. A amostra correspondeu a 64 empresas, para cada ano de análise, que possuíam comitê de auditoria no período de 2010 a 2012. Para a análise dos dados, foram utilizados a estatística descritiva e a análise de regressão linear múltipla, por meio do software SPSS.

Os resultados demonstraram que as variáveis Endividamento (END), Setor de Atuação (SET), empresas auditadas por Big Four (BIG) e Honorários de Não Auditoria (HNA) apresentaram-se significativas, influenciando no prazo de divulgação das demonstrações financeiras. 
Das variáveis relacionadas às características da empresa, verificou-se que o Endividamento (END) possui influência positiva e significante sobre o prazo de publicação das demonstrações financeiras, ou seja, empresas endividadas tendem a divulgar tardiamente suas informações. Os setores de atuação (bens industriais, tecnologia da informação, construção e transporte) possuem influência negativa e significante sobre o prazo de publicação das demonstrações contábeis, cujos resultados convergem com os estudos de Iyoha (2012) e de Ika e Ghazali (2012).

Quanto às variáveis da auditoria independente, concluiu-se que as firmas de auditoria Big Four apresentaram uma relação negativa e significativa com o prazo de divulgação das demonstrações financeiras, o que indica que o prazo de divulgação menor ocorre com as empresas auditadas pelas Big Four. Em relação aos honorários de não auditoria, contatou-se uma relação positiva e significativa, influenciando um prazo de divulgação maior das demonstrações financeiras. Estes achados convergem com os estudos de Ahmed (2003), Al-Ajmi (2008), Afify (2009) e Ika e Ghazali (2012).

Destaca-se o resultado obtido com as variáveis relacionadas às características do comitê de auditoria, no qual se identificou que o tamanho do comitê de auditoria, a independência e a expertise dos membros não possuem influência significativa com o prazo de publicação das demonstrações financeiras. Este resultado refuta o entendimento de que este comitê, por possuir função de primar por bons controles internos e por acompanhar o processo de elaboração das demonstrações financeiras, atrelado às características que a literatura tem sugerido como elementos de eficácia deste órgão, influenciaria prazo das demonstrações financeiras.

Sugere-se, para trabalhos futuros, efetuar estudo de cunho qualitativo por meio de entrevistas aos responsáveis pela controladoria das empresas com menor prazo de publicação e com maior prazo de publicação das demonstrações financeiras para identificar fatores que possam refletir no prazo da publicação. Tais achados também podem ser confrontados com opiniões de especialistas e profissionais de mercado de capitais, objeto de outro estudo.

\section{Referências}

Abernathy, J. L., Herrmann, D., Kang, T., \& Krishnan, G. V. (2013). Audit committee financial expertise and properties of analyst earnings forecasts. Advances in Accounting, 29(1), pp. 1-11. http://dx.doi. org/10.1016/j.adiac.2012.12.001.

Abidin, S., \& Ahmad-Zaluki, N. A. (2012). Auditor industry specialism and reporting timeliness. Procedia-Social and Behavioral Sciences, 65, pp. 873-878. doi: 10.1016/j.sbspro.2012.11.213.

Afify, H. A. E. (2009). Determinants of audit report lag: Does implementing corporate governance have any impact? Empirical evidence from Egypt. Journal of Applied Accounting Research, 10(1), pp. 5686. doi 10.1108/09675420910963397.

Ahadiat, N. (2011). Association between audit opinion and provision of non-audit services. International Journal of Accounting \& Information Management, 19(2), pp. 182-193. doi: $10.1108 / 18347641111136463$

Ahmed, K. (2003). The timeliness of corporate reporting: A comparative study of South Asia. Advances in International Accounting, 16, pp. 17-43. doi:10.1016/S0897-3660(03)16002-3.

Al-Ajmi, J. (2008). Audit and reporting delays: Evidence from an emerging market. Advances in Accounting, 24(2), pp. 217-226. doi:10.1016/j.adiac.2008.08.002.

Alkhatib, K. \& Marji, Q. (2012). Audit Reports Timeliness: Empirical Evidence from Jordan. Procedia-Social and Behavioral Sciences, 62, pp. 1342-1349. doi: 10.1016/j.sbspro.2012.09.229.

Begley, J. \& Fischer, P. E. (1998). Is there information in an earnings announcement delay? Review of accounting studies, 3(4), pp. 347-363. 
Bushman, R., Chen, Q., Engel, E., \& Smith, A. (2004). Financial accounting information, organizational complexity and corporate governance systems. JournalofAccountingandEconomics, 37(2), pp. 167-201.

Conselho Federal de Contabilidade. Data limite para elaboração das demonstrações contábeis. Recuperado em 27 de outubro, $2015:<$ http://portalcfc.org.br/coordenadorias/fiscalizacao/faq/faq.php?id=6396>.

Corrar, L. J., Paulo, E., \& Dias Filho, J. M. (2009). Análise Multivariada para os Cursos de Administração, Ciências Contábeis e Economia. São Paulo: Atlas.

Cullinan, C. P.,Wang, F., Yang, B., \& Zhang, J. (2012).Audit opinion improvement and the timing of disclosure. Advances in Accounting, 28(2), pp. 333-343.

Defond, M. L., Hann, R. N., \& Hu, X. (2005). Does the market value financial expertise on audit committees of boards of directors? Journal of accounting research, 43(2), pp. 153-193.

doi: 10.1111/j.1475-679x.2005.00166

Dezoort, F. T., Hermanson, D. R., \& Houston, R. W. (2003). Audit committee support for auditors: The effects of materiality justification and accounting precision. Journal of Accounting and Public Policy, 22(2), pp. 175-199.doi:10.1016/S0278-4254(03)00007-3

Falcão, E. (1995). Divulgação em demonstrações financeiras de companhias abertas. Caderno de estudos, 12, pp. 01-13.

Fávero, L. P., Belfiore, P., Silva, F. L., \& Chan, B. L. (2009). Análise de Dados: Modelagem Multivariada para tomada de decisões. Rio de Janeiro: Elsevier.

Healy, P. M. \& Palepu, K. G. (2001). Information asymmetry, corporate disclosure, and the capital markets: A review of the empirical disclosure literature. Journalofaccountingandeconomics, 31(1), pp. 405-440.PII: S0165-4101 (01) 00018 - 0

IBGC - Instituto Brasileiro de Governança Corporativa (2009). Guia de Orientação para melhores práticas de Comitês de Auditoria. Cadernos de Governança Corporativa. São Paulo: IBGC, 2009. Recuperado em 17 dezembro, 2013, http://www.ibgc.org.br/CadernoGovernanca.aspx?CodCaderno=53.

Ika, S. R. \& Ghazali, N. A. M. (2012). Audit committee effectiveness and timeliness of reporting: Indonesian evidence. Managerial Auditing Journal, 27(4), pp. 403-424.

Iyoha, F. O. (2012). Company attributes and the timeliness of financial reporting in Nigeria. Business Intelligence Journal, 5(1), pp. 41-49.

Kirch, G., Lima, J. B. N., \& Terra, P. R. S. (2012).Determinants of disclosure timing for financial statements of Brazilian public companies. Revista Contabilidade \& Finanças, 23(60), pp. 173-186.

Krishnan, J. (2005). Audit Committee quality and internal control: an empirical analysis. The AccountingReview. 80(2), pp. 649-675.

Lei no 6.404, de 15 de dezembro de 1976. Dispõe sobre as Sociedades por Ações. . Diário Oficial da União. Brasília, DF: Presidência da República.

Marôco, J. (2011). Análise Estatística com o SPSS statistics. 5aed. Pero Pinheiro: ReportNumber.

Martins, G. A. \& Theóphilo, C. R. (2007). Metodologia da investigação científica para ciências sociais aplicadas. São Paulo: Atlas.

Mironiuc, M.,Chersan, I., \& Robu, I. (2013). Ethics in Providing Non-Audit Services to Ensure Transparency in Financial Reporting. Procedia-Social and Behavioral Sciences, 81, pp. 474-478.doi: 10.1016/j. sbspro.2013.06.463

Mironiuc, M. \&Robu, I. (2012). Empirical study on the analysis of the influence of the audit fees and non audit fees ratio to the fraud risk. Procedia-Social and Behavioral Sciences, 62, pp. 179-183. doi: 10.1016/j.sbspro.2012.09.028. 
Pronunciamento Técnico CPC 00 (R1) (2011). Estrutura Conceitual para Elaboração e Divulgação de Relatório Contábil-Financeiro.Brasília, 02 de Dezembro de 2011.

Pucheta-Martínez, M. C. \& Fuentes, C. (2007). The impact of audit committee characteristics on the enhancement of the quality of financial reporting: An empirical study in the Spanish context. Corporate Governance: An International Review, 15(6), pp. 1394-1412. doi:10.1111/j.1467-8683.2007.00653.x

Sengupta, P. (2004). Disclosure timing: Determinants of quarterly earnings release dates. Journal of Accounting and Public Policy, 23(6), pp. 457-482. doi:10.1016/j.jaccpubpol.2004.10.001.

Solomon, S,Reckers, P. MJ \& Lowe, D. J. (2005). The impact of management image and non-audit service fees on investors' perceptions of earnings quality. Advances in Accounting, 21, pp. 199-216.

Soltani, B. (2002). Timeliness of corporate and audit reports: Some empirical evidence in the French context. The International Journal of Accounting, 37(2), pp. 215-246.

Song, J. \& Windram, B. (2004). Benchmarking audit committee effectiveness in financial reporting. International Journal of Auditing, 8(3), pp. 195-205. doi: 10.1111/j.1099-1123.2004.00090.x.

Vlaminck, N. \& Sarens, G. (2012).The relationship between audit committee characteristics and financial statement quality: evidence from Belgium. In: European Accounting Association, Annual Congress, 35 . 